\title{
Salmonella and Enterohemorrhagic Escherichia coli Serogroups 045, 0121, 0145 in Wheat Flour: Effects of Long-Term Storage and Thermal Treatments
}

\author{
Fereidoun Forghani*, Meghan den Bakker, Jye-Yin Liao, Alison S. Payton, \\ Alexandra N. Futral and Francisco Diez-Gonzalez
}

Center for Food Safety, College of Agricultural and Environmental Sciences, University of Georgia, Griffin, GA, United States

OPEN ACCESS

Edited by: Michael Gänzle,

University of Alberta, Canada

Reviewed by:

Hui Li,

Institute of Agricultural Quality Standards and Testing Technology for Agro Products, (CAS), China

Roopesh Syamaladevi,

University of Alberta, Canada

*Correspondence:

Fereidoun Forghan

fereidoun.forghani@uga.edu; fereidoun_forghani@yahoo.com

Specialty section:

This article was submitted to

Food Microbiology,

a section of the journal

Frontiers in Microbiology

Received: 13 August 2018 Accepted: 07 February 2019 Published: 22 February 2019

Citation:

Forghani F, den Bakker M Liao J-Y, Payton AS, Futral AN and Diez-Gonzalez F (2019) Salmonella and Enterohemorrhagic Escherichia coli Serogroups O45, O121, 0145 in Wheat Flour: Effects of Long-Term

Storage and Thermal Treatments.

Front. Microbiol. 10:323. doi: 10.3389/fmicb.2019.00323
Salmonella and enterohemorrhagic Escherichia coli (EHEC) are of serious concern in wheat flour and its related products but little is known on their survival and thermal death kinetics. This study was undertaken to determine their long-term viability and thermal inactivation kinetics in flour. Inoculation was performed using mixtures of EHEC serogroups $\mathrm{O} 45, \mathrm{O} 121, \mathrm{O} 145$ and Salmonella followed by storage at room temperature $\left(23^{\circ} \mathrm{C}\right)$ or $35^{\circ} \mathrm{C}$ (for Salmonella). Plate counting on tryptic soy agar (TSA) and enrichment were used to assess long-term survival. For thermal studies, wheat flour samples were heated at 55,60,65, and $70^{\circ} \mathrm{C}$ and cell counts of EHEC and Salmonella were determined by plating. The $\delta$-values were calculated using the Weibull model. At room temperature, EHEC serovars and Salmonella were quantifiable for 84 and 112 days, and were detectable for the duration of the experiment after 168 and 365 days, respectively. The $\delta$-values were 2.0, 5.54, and 9.3 days, for EHEC O121, O45, and O145, respectively, and 9.7 days for Salmonella. However, the only significant difference among all values was the $\delta$-value for Salmonella and serogroup 0121 $(p \leq 0.05)$. At $35^{\circ} \mathrm{C}$, Salmonella counts declined to unquantifiable levels after a week and were not detected upon enrichment after 98 days. Heat treatment of inoculated wheat flour at $55,60,65$, and $70^{\circ} \mathrm{C}$ resulted in $\delta$-value ranges of 20.0-42.9, 4.9-10.0, 2.4-3.2, and 0.2-1.6 min, respectively, for EHEC. The $\delta$-values for Salmonella at those temperatures were 152.2, 40.8, 17.9, and $17.4 \mathrm{~min}$, respectively. The $\delta$-values obtained for Salmonella at each temperature were significantly longer than for EHEC $(p \leq 0.05)$. Weibull model was a good fit to describe the thermal death kinetics of Salmonella and EHEC O45, 0121 and 0145 in wheat flour.

\section{HIGHLIGHTS}

- EHEC and Salmonella can survive for extended periods of time in wheat flour.

- Long-term storage inactivation curves of EHEC and Salmonella were similar. 


\section{- EHEC was more sensitive to heat than Salmonella. \\ - Weibull model was a good fit to describe thermal death kinetics of EHEC and Salmonella. \\ - Flour storage at $35^{\circ} \mathrm{C}$ may be a feasible method for microbial reduction.}

\section{Keywords: wheat flour, enterohemorrhagic Escherichia coli, Salmonella, long-term viability, thermal inactivation} kinetics

\section{INTRODUCTION}

A number of studies have reported that vegetative bacterial species can survive during prolonged storage in dry foods (Eglezos, 2010; Forghani et al., 2018). The traditional process given to wheat grains to produce flour does not normally involve an antimicrobial step which results in a relatively stable microbiological load during flour production (Manthey et al., 2004).

A recent report suggests that the frequency and level of flour contamination may be much higher than previously believed (Mäde et al., 2017). The presence of pathogenic bacteria poses a serious risk to consumers because of cross contamination or consumers handling habits such as ingesting raw cookie dough (Rose et al., 2012). Recently, it has been clear that cereal foods also have the potential to transmit bacterial pathogens such as Salmonella and enterohemorrhagic Escherichia coli (EHEC).

The first account of an outbreak with Salmonella serovar Paratyphi, potentially linked to wheat flour was reported in Australia in 1952 (Eglezos, 2010). Since then, Salmonella has caused outbreaks and recalls in raw flour and its related products around the world (Centers for Disease Control and Prevention, 1998; Marler, 2006; Neil et al., 2012; McCallum et al., 2013). The FDA declared that flour and its derivatives could not be considered as ready-to-eat foods (RTE) due to the possibility of Salmonella presence (U.S. Food \& Drug Administration, 2005). Due to the increased outbreak incidence, Salmonella has been considered a major pathogen in low water activity $\left(\mathrm{a}_{\mathrm{w}}\right)$ foods and has been extensively studied (Sperber, 2007; Centers for Disease Control and Prevention, 2009; Ma et al., 2009). However, not much is known about its survival and heat tolerance in wheat flour.

More recently, EHEC have also become pathogens of concern in wheat flour. EHEC were first recognized during the 1980s and have been predominantly linked to beef and fresh produce (Riley et al., 1983). EHEC includes multiple Shiga toxin-producing E. coli serogroups including the most virulent serovars O26, O45, O103, O111, O121, O145, and O157 (Mondani et al., 2014; Wang et al., 2016). The connection between beef and EHEC O157 has been well established, but other serovars have been involved in cases with other food items (Ludwig et al., 2002). However, the information about their presence in wheat flour has been rather scarce (Richter et al., 1993; Berghofer et al., 2003; Aydin et al., 2009; Sabillón Galeas, 2014).

The first flour related EHEC outbreak in the United States was due to E. coli O157:H7 in 2009. Tainted ready-to-bake cookie dough caused 77 illnesses, 35 hospitalizations, and 10 HUS cases (Neil et al., 2012). In 2016, EHEC O26 and O121 were associated in the first wheat flour outbreak caused by non-O157 EHEC in the United States (Crowe et al., 2017). Sixty-three patients with bloody diarrhea cases were reported in 24 states in the United States, which led to a massive flour recall (Centers for Disease Control and Prevention, 2016). The following year, two separate gastroenteritis outbreaks linked to wheat flour contaminated with EHEC O121 were reported in Canada (Canadian Food Inspection Agency, 2017a). These outbreaks resulted in several recalls and an increased concern for wheat flour safety. The most recent EHEC-related event was reported in Canada in 2017 with contaminated pie and tart shells resulting in recall (Canadian Food Inspection Agency, 2017b).

In an effort to advance our understanding about the risk of EHEC in wheat flour, we recently reported on the long-term survival and thermal inactivation kinetics of EHEC O26, O103, and $\mathrm{O} 157$ in wheat flour (Forghani et al., 2018). That study helped assess the likelihood of EHEC survival during storage, helping build fundamental knowledge on the subject and also tested the viability of EHEC reduction in flour by thermal treatments using linear and Weibull models (Santillana Farakos et al., 2013). It also clearly showed the superiority of Weibull model over linear model to fit thermal death kinetics of EHEC in wheat flour.

In the present study, we determined the long-term survival of EHEC O45, O121, and O145, the remaining three members of the major non-O157 EHEC group to date in wheat flour (Beier et al., 2016). Furthermore, we included Salmonella in the study for comparison as the best characterized pathogen related to dry foods due to its ability to persist for long times under desiccation and also its heat resistance in low $\mathrm{a}_{\mathrm{w}}$ matrices (Lambertini et al., 2016). Finally, pulsed-field gel electrophoresis (PFGE) was applied to assess the frequency of strain recovery in select serogroups during long-term storage to identify survival differences among individual strains.

\section{MATERIALS AND METHODS}

\section{Bacteria and Growth Conditions}

Fifteen EHEC and five Salmonella strains were used in this study including five strains of each EHEC serogroup: O45 (TW09183, TW10121, TW14003, TW07947, TW00965), O121 (TW08980, TW07927, TW08039, I2016000899, I2016012950), and O145 (GS G5578620, 4865/96, TW08087, TW09153, TW05149). EHEC strains I2016000899, and I2016012950 were obtained from the Minnesota Department of Health ${ }^{1}$. All other strains were

\footnotetext{
${ }^{1}$ http://www.health.state.mn.us/
} 
obtained from the Michigan State University STEC Center ${ }^{2}$. Four Salmonella strains (S. Typhimurium 2009K-0300, S. Agona SLR141, S. enteritidis 2415, S. Anatum 6802) were provided by our culture collection at the Center for Food Safety. The last strain, Salmonella Typhimurium (ATCC 14028) was purchased from the American Type Culture Collection ${ }^{3}$.

Strains stock cultures were stored at $-70^{\circ} \mathrm{C}$ in tryptic soy broth (TSB; Difco Laboratories, Sparks, MD, United States) supplemented with $20 \%$ (vol/vol) glycerol. All bacterial cultures were subjected to two consecutive transfers $\left(24 \mathrm{~h}\right.$ at $\left.37^{\circ} \mathrm{C}\right)$ before use. Working stocks of each strain were prepared using Luria-Bertani broth (LB; Difco Laboratories, Sparks, MD, United States), stored at $4^{\circ} \mathrm{C}$ and refreshed on a monthly basis. Inoculation cultures were prepared using these stocks.

\section{Inoculum Preparation}

Each strain was inoculated into $40 \mathrm{~mL}$ tryptic soy broth (TSB; Difco Laboratories, Sparks, MD, United States), and incubated for $24 \mathrm{~h}$ at $37^{\circ} \mathrm{C}$ with $200 \mathrm{rpm}$ shaking, reaching stationary phase at an approximate concentration of $9 \mathrm{Log} \mathrm{CFU} / \mathrm{mL}$. After centrifugation $\left(3,000 \times g, 15 \mathrm{~min}, 4^{\circ} \mathrm{C}\right)$ cell pellets were resuspended in $10 \mathrm{~mL}$ sterile $0.1 \%$ buffered peptone water (BPW). Upon mixing into two $25 \mathrm{~mL}$ suspensions of 5-strain cocktail, suspensions were centrifuged $\left(3,000 \times \mathrm{g}, 10 \mathrm{~min}, 4^{\circ} \mathrm{C}\right)$, supernatants were removed, and the remaining pellets were harvested in $200 \mu \mathrm{l} 0.1 \% \mathrm{BPW}$. The final concentrates were used for flour inoculation.

\section{Inoculation Procedure}

All-purpose wheat flour with an average protein content of $10 \%$ was purchased from a retail store in Griffin, GA, United States. Background microflora of flour bags was enumerated by at least three random measurements of $1 \mathrm{~g}$ samples. Samples were diluted in $9 \mathrm{~mL}$ of sterile $0.1 \%$ BPW (Neogen, Inc., East Lansing, MI, United States) in test tubes and appropriate 10fold serial dilutions were spread plated on tryptic soy agar (TSA; Difco). After incubation $\left(24 \mathrm{~h}\right.$ at $\left.37^{\circ} \mathrm{C}\right)$, bacterial numbers were counted and transformed to Log CFU/g. Flour samples with background flora of $\leq 2 \mathrm{Log} \mathrm{CFU} / \mathrm{g}$ were used for the experiments. The pre-inoculation $\mathrm{a}_{\mathrm{w}}$ of flour was measured at room temperature $\left(23 \pm 1{ }^{\circ} \mathrm{C}\right)$ using a water activity meter (AQUA LAB Model 3TE, Decagon Devices, Pullman, WA, United States).

The concentrated cell suspensions of Salmonella and EHEC cocktails were aseptically spot inoculated into 15 -g flour portions in a sterile stomacher bag (Nasco Whirl-Pak, Janesville, WI, United States) and hand mixed for $5 \mathrm{~min}$. If necessary, mixing was continued until no clumps were observed. Subsequently, $135 \mathrm{~g}$ flour were added to the seeded flour samples and mixed for $3 \mathrm{~min}$ by hand. Finally, two sets of stomaching (Seward Stomacher, 400 Lab System, Norfolk, United Kingdom) for $3 \mathrm{~min}$ at $260 \mathrm{rpm}$ and a $3 \mathrm{~min}$ manual mix were performed.

The developed inoculation procedure resulted in consistent inoculum levels of approximately $8 \mathrm{Log}$ CFU/g. The $\mathrm{a}_{\mathrm{w}}$ was

${ }^{2}$ http://shigatox.net/stec/cgi-bin/index

${ }^{3}$ https://www.atcc.org/ measured after each inoculation as mentioned above. These flour samples $(150 \mathrm{~g})$ were used for the long-term survival studies. For thermal inactivation studies the exact same procedure was performed on $100 \mathrm{~g}$ of flour ( $10 \mathrm{~g}$ flour was seeded $+90 \mathrm{~g}$ ).

\section{Packing and Long-Term Storage}

Stomacher bags of inoculated samples were tightly closed, put inside of a Ziploc ${ }^{\circledR}$ Brand vacuum sealer bag and sealed without vacuuming. Sealed bags of all four sample groups (in duplicate) were put in tightly closed plastic containers and stored at room temperature $\left(23 \pm 1^{\circ} \mathrm{C}\right)$. For Salmonella, an additional storage at $35^{\circ} \mathrm{C}$ was performed to study the effect of storage temperature.

Samples were taken on days $0,3,7,14,21$, and 28 followed by biweekly sampling at day 42 , day 56 , and then every 4 weeks. After reaching the limit of quantification (2 Log CFU/g) by standard microbiological plating, samples were enriched before detection. All bags were re-sealed immediately after each sampling. The last sampling time was 168 days (24 weeks) and 1 year (52 weeks) for EHEC and Salmonella, respectively. Sampling stopped after three consecutive negative results were obtained.

\section{Thermal Inactivation Studies}

Thermal processing was performed using a digital dry bath (Fisher Scientific, Pittsburgh, PA, United States) in $0.5 \mathrm{~mL}$ thin wall PCR tubes with flat caps (Axygen Biosciences, Union City, CA, United States). Treatment temperatures used were 55 (up to $240 \mathrm{~min}$ ), 60 (up to $80 \mathrm{~min}$ ), 65 (up to $70 \mathrm{~min}$ ) and $70^{\circ} \mathrm{C}$ (up to $60 \mathrm{~min}$ ) to obtain thermal death curves for Salmonella and EHEC O45, O121, O145. Each particular temperature treatment was performed on 1 day, beginning from day 3, postinoculation.

Based on our preliminary studies (data not shown) for each target temperature the dry bath block temperature was set two degrees higher, resulting in the exact desired temperature inside the tubes. Temperature inside tubes was verified at five random locations using a thermocouple bead wire temperature probe attached to a portable thermometer (HH series; OMEGA Engineering Inc. Stamford, CT, United States). Subsequently, come-up times were measured.

Inoculated flour samples $(0.33 \pm 0.02 \mathrm{~g})$ with each fivestrain Salmonella or EHEC cocktail were treated at once with the same time intervals for each specific temperature. Following thermal treatment the tubes were immediately placed in ice-water for one min to stop inactivation before being subjected to microbiological analyses. In addition, after the longest treatment time in each thermal treatment temperature, contents of three tubes (approximately $1 \mathrm{~g})$ were rapidly transferred to the water activity meter plastic sample containers and their water activities were immediately measured.

\section{Microbiological Analyses}

Triplicate $1 \mathrm{~g}$ portions were taken from duplicate $150 \mathrm{~g}$ flour bags at each sampling interval, 10 -fold serial dilutions in $0.1 \%$ BPW (Neogen, Inc., East Lansing, MI, United States) were prepared and spread plated on TSA. Following incubation at $37^{\circ} \mathrm{C}$ for 
$24 \mathrm{~h}$, colonies were counted and transformed into Log CFU/g for microbiological analysis.

Un-inoculated flour samples were tested to determine background aerobic plate count. After reaching the limit of detection without enrichment, three 1-g samples from each stored bag were transferred to $40 \mathrm{~mL}$ of lauryl tryptose broth (LTB; Difco) or TSB (Difco) for EHEC and Salmonella, respectively, and enriched for 24 to $48 \mathrm{~h}$ at $37^{\circ} \mathrm{C}$ with 200 rpm shaking.

Appropriate dilutions of the pre-enriched EHEC homogenates were spread plated on sorbitol MacConkey agar (SMAC; Difco) supplemented with $0.05 \mathrm{mg} / \mathrm{L}$ cefixime and $2.50 \mathrm{mg} / \mathrm{L}$ potassium tellurite (Sigma-Aldrich, Inc., St. Louis, MO, United States) (CT-SMAC) (Ludwig et al., 2002) or loaded onto 3M Petrifilm E. coli/Coliform Count Plate (6404, 3M Microbiology, St. Paul, MN, United States) according to the manufacturer's guidelines and incubated at $37^{\circ} \mathrm{C}$ for $24 \mathrm{~h}$. For Salmonella, xylose lysine deoxycholate agar (XLD; Difco) was used.

All presumptive EHEC colonies recovered from TSA and CTSMAC were confirmed using serogroup specific agglutination test (Cedarlane, Burlington, ON, Canada). For Salmonella black colonies on XLD agar were further confirmed as Salmonella, using agglutination test as well (Salmonella $\mathrm{H}$ Antiserum Poly a-z; Difco). For the analysis of thermally treated samples, tube contents were transferred to $9.7 \mathrm{~mL} 0.1 \% \mathrm{BPW}$ and appropriate 10-fold serial dilutions were spread plated on TSA for microbial enumeration. Colony counts were transformed to Log CFU/g and used for data analysis.

\section{Data and Statistical Analysis}

Survival counts were calculated according to Food and Drug Administration's Bacteriological Analytical Manual's formula for aerobic plate counts modified for $0.1 \mathrm{~mL}$ plating volumes (Maturin and Peeler, 1998). Average values of triplicate measurements at each sampling time were used with a minimum of two replicate trials for each test $(n=6)$.

Weibull model (Mafart et al., 2002) was fit to the obtained data using Microsoft Excel 2016 Add-in GinaFit Version 1.7 (Geeraerd et al., 2005).

Weibull model (Mafart et al., 2002):

$$
\log \left(N_{\mathrm{t}}\right)=\log \left(N_{0}\right)-(t / \delta)^{\beta}
$$

Based on the definitions by Mafart et al. (2002), $N_{\mathrm{t}}$ is the population at time $t(\mathrm{CFU} / \mathrm{g}), N_{0}$ is the population at time 0 $(\mathrm{CFU} / \mathrm{g}), \delta$ is the time required for the first decimal reduction $(\mathrm{min})$ and $\beta$ is a fitting parameter that describes the shape of the curve ( $\beta>1$ convex, $\beta<1$ concave). Finally, to further evaluate the developed Weibull model, the equation was solved using $N_{0}$ obtained from the actual data and $\delta$ - and $\beta$-values obtained from the model for each data point.

While decimal reduction means a $90 \%$ reduction in the survival counts, parameter $\delta$ is distinguished from the conventional $D$-value since it shows the first decimal reduction while in contrast $D$-value which is derived from the linear first-order kinetic represents the time of decimal reduction, regardless of the heating time.
Water activities of all flour bags used, means of inactivation parameters in survival counts (Log CFU/g) from long-term storage and thermal inactivation tests were subjected to $t$-test and analysis of variance (ANOVA), respectively. Tukey's multiple range test was applied for the long-term survival and analysis of values obtained from the same temperature treatments. Fisher's least significant difference (LSD) test was applied for the comparison of different treatment temperatures in each serogroup. All analyses were performed using IBM SPSS Statistics Version 24 (SPSS Institute, Chicago, IL, United States). The significance of difference was defined at $p \leq 0.05$.

\section{Pulsed-Field Gel Electrophoresis}

Pulsed-field gel electrophoresis was performed using the standardized PulseNet's laboratory protocol ${ }^{4}$ with minor modifications on two select serogroups. Random single colonies of EHEC O121 at days 21,42,56, and 84 of storage and EHEC O45 at day 168 of storage were selected for PFGE. Subsequently, PFGE was performed on these colonies along with the five representative strains of each individual serogroup for identification using comparison of PFGE band patterns.

Briefly, single colonies grown in TSB (Difco) at $37^{\circ} \mathrm{C}$ overnight were streaked onto TSA with $5 \%$ sheep blood (Northeast Laboratory, Waterville, ME, United States) and incubated at $37^{\circ} \mathrm{C}$ for $14-18 \mathrm{~h}$. Using sterile swabs, bacterial colonies were suspended in $2 \mathrm{~mL}$ of cell suspension buffer (100 mM Tris, $100 \mathrm{mM}$ EDTA, $\mathrm{pH}$ 8.0) in $12 \mathrm{~mm} \times 75 \mathrm{~mm}$ tubes (Falcon 2054; Corning, NY, United States). Cell concentrations were adjusted to optical density of 0.45 at $610 \mathrm{~nm}$ wavelength using a spectrophotometer (MicroScan Turbidity Meter, Simens Healthcare Diagnostics Inc., West Sacramento, CA, United States).

Following concentration adjustment, $400 \mu \mathrm{L}$ cell suspensions were mixed with $400 \mu \mathrm{L}$ of melted 1\% SeaKem Gold Agarose (SKG; Lonza, Basel, Switzerland) cooled to $60^{\circ} \mathrm{C}$ and 20 $\mu \mathrm{L}$ of $20 \mathrm{mg} / \mathrm{mL}$ Proteinase K (Amresco LLC., Solon, OH, United States) by brief gentle pipetting in $1.5 \mathrm{~mL}$ microcentrifuge tubes. The mixtures were immediately dispensed into wells of reusable plug molds (Bio-Rad Laboratories, Hercules, CA, United States) and stored for $15 \mathrm{~min}$ at room temperature to solidify. Solidified plugs were trimmed and carefully transferred to $50 \mathrm{~mL}$ conical tubes containing $5 \mathrm{~mL}$ of cell lysis buffer (50 mM Tris, $50 \mathrm{mM}$ EDTA, pH 8.0, $1 \%$ sarcosyl) with $0.1 \mathrm{mg} / \mathrm{mL}$ Proteinase K (Amresco; $25 \mu \mathrm{L}$ of $20 \mathrm{mg} / \mathrm{mL}$ stock solution) and incubated at $55^{\circ} \mathrm{C}$ with constant vigorous agitation (200 rpm).

After lysis, plugs were washed twice using $15 \mathrm{~mL}$ of sterile ultrapure water pre-heated to $55^{\circ} \mathrm{C}$ with shaking $(200 \mathrm{rpm})$ for $15 \mathrm{~min}$ and subsequently with $15 \mathrm{~mL}$ of TE buffer $(10 \mathrm{mM}$ Tris, 1 mM EDTA, $\mathrm{pH}$ 8.0) for four times using the same conditions. After the last TE wash, plugs were stored in $5 \mathrm{~mL}$ TE buffer at $4^{\circ} \mathrm{C}$ until restriction digestion. Restriction digestion was performed using XbaI restriction enzyme (Roche Diagnostics, Indianapolis, IN, United States).

\footnotetext{
${ }^{4}$ https://www.cdc.gov/pulsenet/pdf/ecoli-shigella- salmonella-pfge- protocol508c.pdf
} 


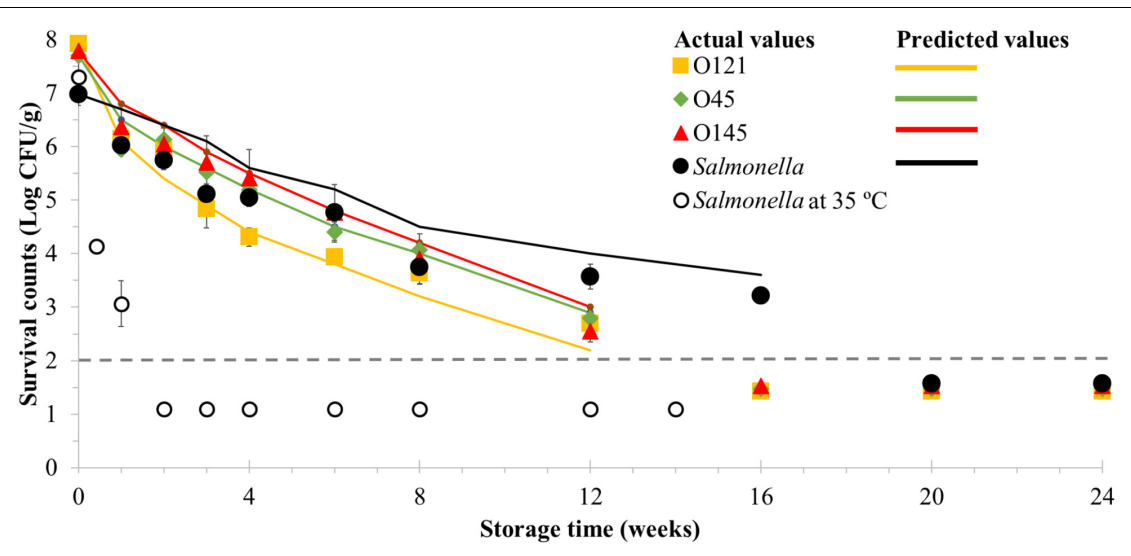

FIGURE 1 | Long-term survival of enterohemorrhagic Escherichia coli serogroups $\mathrm{O} 45, \mathrm{O} 121,0145$ and Salmonella in wheat flour at room temperature $\left(23 \pm 1^{\circ} \mathrm{C}\right)$ for 24 weeks and Salmonella at $35^{\circ} \mathrm{C}(14$ weeks). Time points shown below the detection limit (dashed line) by direct plating ( $2 \mathrm{Log} \mathrm{CFU} / \mathrm{g})$ indicate positive samples after enrichment. Room temperature samples were enriched from weeks 16 and 20 of storage for EHEC and Salmonella, respectively. Values are the Log-transformed number of surviving cells per gram of sample, shown as the mean of at least three independent trials with minimum two replicates with standard error of the mean indicated. Data markers represent the actual values and lines represent the predicted surviving cell numbers calculated by solving the Weibull equation, using $\delta$ - and $\beta$-values obtained from the model for each data point and the actual $N_{0}$ based on actual survival counts (data markers).

The plugs were cut into $2.5 \mathrm{~mm}$ slices and transferred to $1.5 \mathrm{~mL}$ microcentrifuge tubes for restriction digestion. A prerestriction incubation step was performed in which each plug slice was placed in $200 \mu \mathrm{L}$ of $1 \times$ restriction buffer and incubated at room temperature for $15 \mathrm{~min}$. Subsequently, pre-restriction buffer was removed and restriction digestion was performed in $200 \mu \mathrm{L}$ of digestion master mix consisted of $173 \mu \mathrm{L}$ ultrapure water, $20 \mu \mathrm{L} 10 \times$ restriction buffer, $2 \mu \mathrm{L}$ of $10 \mathrm{mg} / \mathrm{mL}$ bovine serum albumin and $5 \mu \mathrm{L}$ of restriction enzyme (50 $\mathrm{U}$ total) incubated at $37^{\circ} \mathrm{C}$ for $2 \mathrm{~h}$.

The enzyme/buffer mixtures were removed and after $5 \mathrm{~min}$ incubation in $0.5 \times$ Tris Borate EDTA (TBE) at room temperature fixed at the bottom of comb teeth for $15 \mathrm{~min}$ followed by gel casting. The $1 \%$ SKG agarose $\left(55^{\circ} \mathrm{C}\right)$ was poured and left to solidify for $45 \mathrm{~min}$. After solidification, DNA restriction fragments were separated with a CHEF-DR ${ }^{\circledR}$ III (Bio-Rad) with pulse times with settings as $6.76 \mathrm{~s}$ initial switch time, $35.38 \mathrm{~s}$ final switch time, $6 \mathrm{~V} / \mathrm{cm}$ voltage, $120^{\circ}$ included angle or $\mathrm{CHEF}$ Mapper (Bio-Rad) using the auto algorithm for non-O157 Shiga toxin-producing E. coli. All PFGE runs were performed at $14^{\circ} \mathrm{C}$

TABLE 1 | Rate of enterohemorrhagic E. coli and Salmonella inactivation in wheat flour stored at room temperature $\left(23 \pm 1^{\circ} \mathrm{C}\right)$ for 84 days (12 weeks) and 112 days (16 weeks), respectively, calculated by the Weibull model ${ }^{1}$.

\begin{tabular}{lccccc}
\hline & \multicolumn{5}{c}{ Weibull model parameters } \\
\cline { 2 - 6 } 8 Bacteria & $\delta$ (days) & $\delta$ SE & $\boldsymbol{\beta}$ & $\boldsymbol{\beta}$ SE & Adj. $\boldsymbol{R}^{\mathbf{2}}$ \\
\hline EHEC 045 & $5.54^{\mathrm{ab}}$ & 1.17 & 0.57 & 0.04 & 0.97 \\
EHEC 0121 & $2.04^{\mathrm{a}}$ & 0.08 & 0.46 & 0.00 & 0.93 \\
EHEC 0145 & $9.34^{\mathrm{ab}}$ & 5.2 & 0.70 & 0.16 & 0.98 \\
Salmonella & $9.67^{\mathrm{b}}$ & 3.06 & 0.56 & 0.07 & 0.91 \\
\hline
\end{tabular}

${ }^{1}$ Within each column, values followed by the different lowercase letters are significantly different $(p \leq 0.05)$. for $18 \mathrm{~h}$ and $20 \mathrm{~min}$ with a $0.5 \times \mathrm{TBE}$ flow rate of $1 \mathrm{~L} / \mathrm{min}$. Salmonella ser. Braenderup H9812 was used as standard control in all experiments.

Gels were stained using SYBR ${ }^{\circledR}$ Safe (S-33102, Invitrogen, Carlsbad, CA, United States) and restriction fragment patterns were photographed by a Gel Doc ${ }^{\mathrm{TM}} \mathrm{XR}^{+}$imaging system (Bio$\mathrm{Rad})$ using an Image $\mathrm{Lab}^{\mathrm{TM}}$ Software. The final images were analyzed with BioNumerics software version 6.6 (Applied Maths Inc., Sint-Martens-Latem, Belgium) and fingerprints data were clustered for identification of randomly selected colonies after long-term storage.

\section{RESULTS}

\section{Background Microbiota and $a_{w}$ of Wheat Flour}

The background aerobic plate count of all flours used in the study was confirmed as $2 \mathrm{Log} \mathrm{CFU} / \mathrm{g}$ or less. All flour samples used for long-term survival had $\mathrm{a}_{\mathrm{w}}$ of 0.50 and 0.57 pre- and post-inoculation, respectively. This was equivalent to maximum $\mathrm{a}_{\mathrm{W}}$ differences of approximately 0.09 between pre- and postinoculation. In flour samples used for thermal inactivation tests $\mathrm{a}_{\mathrm{w}}$ values measured pre- and post-inoculation were 0.45 and 0.52 , respectively, showing an $\mathrm{a}_{\mathrm{w}}$ difference of less than 0.09 . No significant difference was observed between the $a_{w}$ of the flour samples bought or between samples pre- and post-inoculation. Samples $\mathrm{a}_{\mathrm{w}}$ did not change during storage (data not shown).

The standard deviation of the counts obtained from six post-inoculation subsamples (1 $\mathrm{g}$ each) of each EHEC serogroup and Salmonella in each measurement was $\leq 0.3 \mathrm{Log}$ $\mathrm{CFU} / \mathrm{g}$, confirming the homogeneous inoculum mixing during inoculation process. Also, measurements before and after the thermal treatments at their longest time point resulted in less than 0.052 change in $\mathrm{a}_{\mathrm{w}}$, regardless of treatment temperature. 


\section{Long-Term Survival of Salmonella and EHEC in Flour}

There were approximately 1 Log CFU/g reductions of the initial viable counts after the first 4 days followed by approximately $0.5 \mathrm{Log}$ CFU/g declines up to 10 days of storage for the three EHEC serogroups and Salmonella stored at room temperature (Figure 1). During the subsequent 4 weeks the reduction rates slowed down to approximately $0.5 \mathrm{Log} \mathrm{CFU} / \mathrm{g}$ per week, and then to approximately $0.3 \mathrm{Log} \mathrm{CFU} / \mathrm{g}$ per week until day 84 of storage, which was the last time point that surviving EHEC was quantified by direct plating.

Between weeks 8 and 16, the Salmonella survival rate had a slower decline compared to EHEC, which resulted in its quantification at least 4 weeks beyond. Viable cells of EHEC O45, O121, and O145 and Salmonella were still detected in wheat flour at 168 days of storage at room temperature $\left(23 \pm 1{ }^{\circ} \mathrm{C}\right)$ which was the last time point of sampling for EHEC (Figure 1). In case of Salmonella, positive samples were still recovered after 1 year, which was the last sampling time point for Salmonella. The fastest reductions in both viable EHEC and Salmonella were observed in the early post-inoculation days. All EHEC serogroups had similar survival curves with multiple overlapping time points within the time-course curves. Furthermore, the same trend was also observed for Salmonella up to week 8 of storage.

Wheat flour inoculated with Salmonella was also stored at $35^{\circ} \mathrm{C}$ and the viability was determined (Figure 1). A decline of more than approximately $1 \mathrm{Log} \mathrm{CFU} / \mathrm{g}$ was observed in the first 4 days of storage and samples after 1 week of storage were the last ones to be quantifiable without enrichment. Enrichment was performed from the second week of storage and resulted in positive recovery of Salmonella during no more than 98 days (14 weeks) of storage.

\section{Long-Term Inactivation Kinetics of EHEC and Salmonella in Wheat Flour}

The calculation of the parameters of inactivation kinetics of EHEC and Salmonella stored at room temperature $\left(23 \pm 1^{\circ} \mathrm{C}\right)$ were determined with data points obtained during 84 and 112 days, respectively (Table 1 ). First decimal reduction times ( $\delta$ ) of serogroups O45, O121, O145 and Salmonella as 5.54, 2.04, 9.34, and 9.67 days, respectively, were calculated using the Weibull model.

While none of the $\delta$-values were significantly different $(p>0.05)$ among the EHEC serogroups, the Salmonella $\delta$-value was significantly different from one of the serogroups, O121 $(p \leq 0.05)$. The Adj. $R^{2}$ values of the Weibull model were in the range of $0.91-0.97$, clearly showing the good fit of Weibull model for EHEC and Salmonella death kinetics during long-term storage at room temperature $\left(23 \pm 1^{\circ} \mathrm{C}\right)$.

\section{Thermal Inactivation Kinetics of EHEC and Salmonella in Wheat Flour}

In general, come-up times were shorter as temperatures increased gradually. Briefly, at 60,65 , and $70^{\circ} \mathrm{C}$ it took samples between 30 and $50 \mathrm{~s}$ to reach to $1-2^{\circ} \mathrm{C}$ lower than the desired temperature. From there, a maximum of $30 \mathrm{~s}$ time was needed to reach the unified set temperature throughout the sample inside the $0.5 \mathrm{~mL}$ tubes $\left(60,65,70^{\circ} \mathrm{C}\right)$. The come-up time was a little longer for the $55^{\circ} \mathrm{C}$ samples compared to the other higher temperatures. It took approximately $90 \mathrm{~s}$ to reach $1-2^{\circ} \mathrm{C}$ lower than the desired temperature and another $30 \mathrm{~s}$ to reach the exact temperature $\left(55^{\circ} \mathrm{C}\right)$.

The viable counts of all serovars and Salmonella declined more rapidly after inoculated flour samples were heated at any temperature at the beginning, but the reduction rate slowed down later during incubation (Figure 2). This trend was more noticeable for Salmonella, when its counts remained almost similar throughout the treatment period after the initial decrease. The three EHEC serovars had inactivation curves that resembled each other at each particular temperature. Overall, after $60 \mathrm{~min}$ of thermal treatment at $55,60,65$, and $70^{\circ} \mathrm{C}$ average microbial count reductions of $1.57,2.36,3.44$, and $4.22 \mathrm{Log} \mathrm{CFU} / \mathrm{g}$ for the three EHEC combined, and 0.90, 1.14, 1.79, and $1.91 \mathrm{Log}$ CFU/g for Salmonella, were achieved, respectively.

The Weibull model was employed to determine the thermal inactivation kinetics parameters of EHEC serogroups and Salmonella at 55, 60, 65, and $70^{\circ} \mathrm{C}$ (Table 2). Same as in room temperature storage Weibull model was a good fit. The Adj. $R^{2}$ values for EHEC $\delta$-values were in the range of $0.85-0.98$. The same values were in the range of 0.71-0.94 for Salmonella.

No significant difference was observed among the $\delta$-values of different EHEC serogroups at each treatment temperature obtained by Weibull model. However, for Salmonella $\delta$-values were always significantly different from EHEC $(p \leq 0.05)$, regardless of the treatment temperature. The $5^{\circ} \mathrm{C}$ increments in treatment temperature both for each EHEC serogroup as well as Salmonella always resulted in decline of $\delta$-values, but the differences at higher temperatures were not always significant. At $70^{\circ} \mathrm{C}$, the $\delta$-values were $1.55,0.17,0.76$, and $17.36 \mathrm{~min}$ for serogroups O45, O121, O145, and Salmonella, respectively.

\section{PFGE Pattern Analysis}

The PFGE dendrogram of randomly selected EHEC isolates from serogroup O121 at days 56 and 84 of storage and serogroup O45 at day 168 of storage along with the patterns obtained from the known isolates of each serogroup were used for identification (Figure 3). For serogroup O121, the two isolates from day 56 and the two from day 84 of storage were all identified as either I2016000899 or I2016012950 (Figure 3A). In case of EHEC serogroup $\mathrm{O} 45$, one of the random isolates from day 168 of storage was identified as TW00965 and all the other three as TW07947 (Figure 3B).

\section{DISCUSSION}

The information available about EHEC long-term survival in wheat flour was very limited until our recent study (Forghani et al., 2018), in which we reported survival and thermal inactivation of EHEC serovars O26, O103, O111, and O157 in wheat flour. Such information was important to the industry due to the fact that product composition such as the unique composition of wheat flour may affect the rate of microbial 

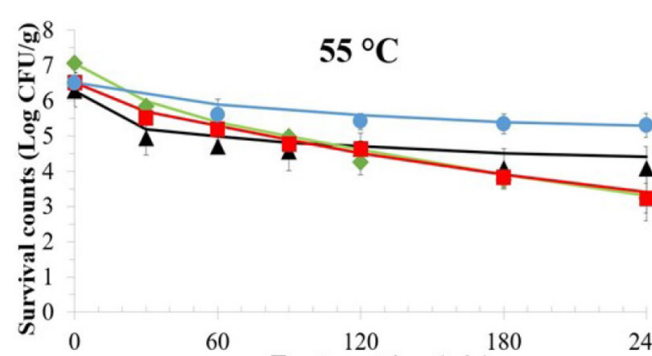

$55^{\circ} \mathrm{C}$

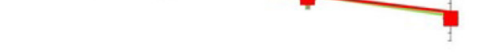

Actual values

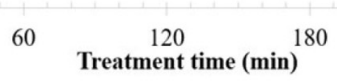

240

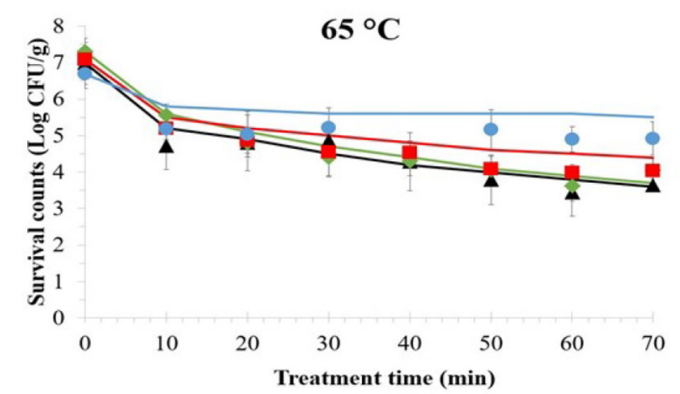

$-0121$

$\triangle \mathrm{O} 45$

8

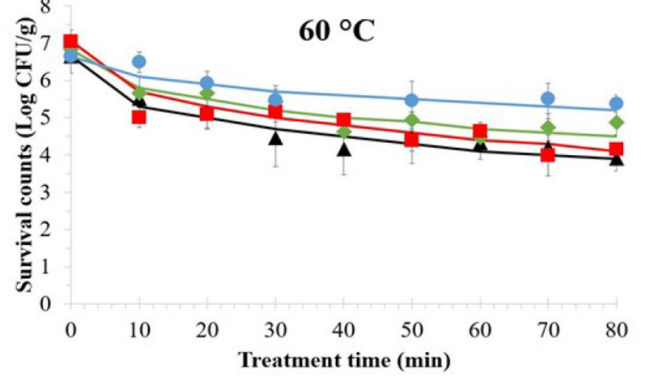

Predicted values

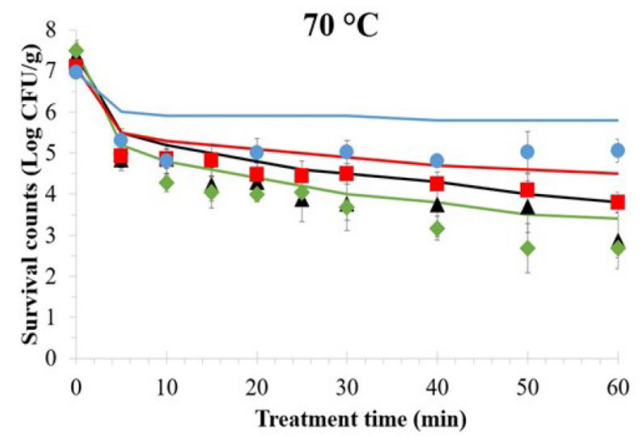

FIGURE 2 | Thermal inactivation curves of enterohemorrhagic Escherichia coli serogroups $\mathrm{O} 45, \mathrm{O} 121,0145$, and Salmonella in wheat flour at $55,60,65$, and $70^{\circ} \mathrm{C}$. Values are the Log-transformed number of surviving cells per gram of sample, shown as the mean of at least three independent trials with minimum two replicates with standard error of the mean indicated. Data markers represent the actual values and lines represent the predicted surviving cell numbers calculated by solving the Weibull equation, using $\delta$ - and $\beta$-values obtained from the model for each data point and the actual $N_{0}$ based on actual survival counts (data markers).

inactivation (Santillana Farakos et al., 2014). The EHEC (O26, O103, O111, and O157) survived in wheat flour stored at room temperature $\left(23 \pm 1^{\circ} \mathrm{C}\right)$ for 1 year and survival was much lower as storage temperature increased to $35^{\circ} \mathrm{C}$. This finding was in agreement with the previously reported results that indicated the survival of bacteria was favored by reduced $\mathrm{a}_{\mathrm{w}}$ and temperature (Beuchat et al., 2013).

To further expand the knowledge on EHEC risk assessment of wheat flour and to be able to better predict their process lethality, in the present study three additional EHEC serogroups not included in the previous study (O45, O121, O145) were assessed. Also, Salmonella was included for comparison as a major pathogen of concern in dry foods including flour and related products. Thus in the present paper, we included assessing Salmonella long-term survival at room temperature and thermal death kinetics at $55,60,65$, and $70^{\circ} \mathrm{C}$ in wheat flour. In addition, Salmonella survival was studied at $35^{\circ} \mathrm{C}$ for comparison with similar data on EHEC obtained in our previous study (Forghani et al., 2018). These temperatures were selected because it was unlikely that they had negative influence on the wheat flour properties (Ozawa et al., 2009; Khamis, 2014; Sudha et al., 2016) for the amount of time that they were used in the study.

Due to the importance of inoculation method in challenge food studies and in particular dry foods (Hildebrandt et al., 2016; Esbelin et al., 2018; Limcharoenchat et al., 2018) a method based on application of concentrated cell suspension for inoculation was developed in our previous study (Forghani et al., 2018). This method could efficiently deliver as high as approximately $8 \mathrm{Log}$
CFU/g inoculum level homogeneously, did not show variabilities which are of concern for inoculation (Blessington et al., 2013; Beuchat et al., 2017) and barely changed the water activity of postinoculation wheat flour. We also considered that it was important to maintain the same conditions for EHEC and Salmonella to maximize the accuracy of comparisons.

Reduction of $\mathrm{a}_{\mathrm{w}}$ is one of the main strategies to control microbial contamination and growth in food matrices due to inhibition of enzymatic reactions and metabolism in low $\mathrm{a}_{\mathrm{w}}$ (Maserati et al., 2017). It is also well established that $a_{w}$ is a key factor influencing the survival of Salmonella in thermal processing as increase in $\mathrm{a}_{\mathrm{w}}$ will result in decrease in the thermal resistance (Xu et al., 2018). Furthermore, decreasing $\mathrm{a}_{\mathrm{w}}$ may also enable bacteria to survive longer (Podolak et al., 2012).

Salmonella long-term survival was previously reported in other low $\mathrm{a}_{\mathrm{w}}$ matrices such as peanut flour (Kataoka et al., 2014), pasta (Rayman et al., 1979), raw pecan and peanut kernels (Brar et al., 2015) stored at room temperature for 1 year. It was also reported to survive in cracker sandwiches and cookie stored at $25^{\circ} \mathrm{C}$ for at least 182 days (Beuchat and Mann, 2015). The present work advanced our understanding on Salmonella longterm survival in wheat flour reporting that flour was still positive for Salmonella after 1 year post-inoculation at $23^{\circ} \mathrm{C}$.

E. coli $\mathrm{O} 157, \mathrm{O} 111$ and $\mathrm{O} 26$ were previously reported to survive for 113 days in mallow stored at $22^{\circ} \mathrm{C}$ at a $\mathrm{a}_{\mathrm{w}}$ of 0.73 with inoculum levels of $4 \mathrm{Log} \mathrm{CFU} / \mathrm{g}$. In the same study, survival was only 90 and 42 days for chocolate $\left(\mathrm{a}_{\mathrm{w}}: 0.40\right)$ and biscuit cream $\left(\mathrm{a}_{\mathrm{w}}: 0.75\right)$, respectively, emphasizing the effect of matrix 
TABLE 2 | Thermal inactivation rates of enterohemorrhagic E. coli and Salmonella in wheat flour calculated by Weibull model.

\begin{tabular}{|c|c|c|c|c|c|c|}
\hline \multirow[t]{2}{*}{ Bacteria } & \multirow[b]{2}{*}{$\begin{array}{r}\text { Temp } \\
\left({ }^{\circ} \mathrm{C}\right)\end{array}$} & \multicolumn{5}{|c|}{ Weibull model parameters } \\
\hline & & $\begin{array}{c}\delta \\
(\min )\end{array}$ & $\begin{array}{l}\delta \\
\text { SE }\end{array}$ & $\beta$ & $\begin{array}{l}\beta \\
\text { SE }\end{array}$ & $\begin{array}{c}\text { Adj. } \\
R^{2}\end{array}$ \\
\hline \multirow[t]{4}{*}{ EHEC O45 } & 55 & $\mathrm{~B}_{20.04^{\mathrm{a}}}$ & 8.06 & 0.26 & 0.09 & 0.87 \\
\hline & 60 & $\mathrm{AB}_{5.24} \underline{\mathrm{a}}$ & 2.35 & 0.37 & 0.06 & 0.87 \\
\hline & 65 & $\mathrm{~A}_{2.76^{a}}$ & 0.86 & 0.38 & 0.03 & 0.85 \\
\hline & 70 & $\mathrm{~A}_{1.55^{\mathrm{a}}}$ & 1.51 & 0.31 & 0.13 & 0.92 \\
\hline \multirow[t]{4}{*}{ EHEC 0121} & 55 & ${ }^{B} 26.57^{a}$ & 9.14 & 0.60 & 0.10 & 0.98 \\
\hline & 60 & $\mathrm{AB}_{10.06} \underline{\mathrm{a}}$ & 2.17 & 0.41 & 0.00 & 0.93 \\
\hline & 65 & $\mathrm{~A}_{3.19^{a}}$ & 1.29 & 0.42 & 0.07 & 0.95 \\
\hline & 70 & ${ }^{\mathrm{A}} 0.17^{\mathrm{a}}$ & 0.11 & 0.24 & 0.03 & 0.95 \\
\hline \multirow[t]{4}{*}{ EHEC 0145} & 55 & ${ }^{\mathrm{B}} 42.86^{\mathrm{a}}$ & 2.41 & 0.66 & 0.01 & 0.98 \\
\hline & 60 & $\mathrm{~A}_{4.86} \underline{\mathrm{a}}$ & 0.82 & 0.38 & 0.02 & 0.89 \\
\hline & 65 & $\mathrm{~A}_{2} .37^{a}$ & 0.11 & 0.29 & 0.03 & 0.95 \\
\hline & 70 & ${ }^{\mathrm{A}} 0.76^{\mathrm{a}}$ & 0.75 & 0.20 & 0.09 & 0.93 \\
\hline \multirow[t]{4}{*}{ Salmonella } & 55 & $\mathrm{~A}_{152.22^{\mathrm{b}}}$ & 125.32 & 0.27 & 0.07 & 0.94 \\
\hline & 60 & $\mathrm{~A}_{40.78} \underline{\mathrm{b}}$ & 14.63 & 0.46 & 0.09 & 0.82 \\
\hline & 65 & $A_{17.89^{b}}$ & 16.14 & 0.11 & 0.05 & 0.83 \\
\hline & 70 & $A_{17.36^{\mathbf{b}}}$ & 17.00 & 0.04 & 0.04 & 0.71 \\
\hline
\end{tabular}

Values marked with different uppercase letters within each individual EHEC serogroup and Salmonella are significantly different. Values for the same treatment temperature $\left(55^{\circ} \mathrm{C}:\right.$ a $, 60^{\circ} \mathrm{C}: \underline{a}, 65^{\circ} \mathrm{C}:$ a, $70^{\circ} \mathrm{C}$ : a) within each column followed by different lowercase letters are significantly different ( $p \leq 0.05$ ).

type on survival (Baylis et al., 2004). In other studies E. coli O157:H7 survived on walnut kernels at $23^{\circ} \mathrm{C}$ (Blessington et al., 2012) and peanut and pecan kernels at $22^{\circ} \mathrm{C}$ for at least 12 months (Brar et al., 2015). Results from our previous study (Forghani et al., 2018), in agreement with the above mentioned reports revealed that EHEC O26, O103, O111, and O157 survived for at least 1 year in wheat flour stored at $23^{\circ} \mathrm{C}$. In the present study, the inactivation curves of EHEC O45, O121, and O145 perfectly aligned with our previous study and therefore sampling was stopped at day 168 of storage.

The long-term survival of pathogens in flour should be of further concern to the food safety specialists and industry as Salmonella and E. coli may not be the only sources of risk. For example, a recent study reported extended stability of Listeria monocytogenes in wheat flour for up to 210 days at room temperature, as well as its enhanced thermal resistance in flour with 0.31 and $0.56 \mathrm{a}_{\mathrm{w}}$ (Taylor et al., 2018). Longterm inactivation kinetics of EHEC O45, O121, and O145 were consistent among serogroups. Based on the adjusted $R^{2}$ values obtained, in agreement with previous studies, in this study the Weibull model was found to be suitable for studying the death kinetics of EHEC and Salmonella in wheat flour (Ma et al., 2009; Santillana Farakos et al., 2014; Rachon et al., 2016; Forghani et al., 2018).

Generally, survival of bacteria in low $\mathrm{a}_{\mathrm{w}}$ foods is reduced as temperature increases (Beuchat et al., 2017). For instance, E. coli survived in chocolate $\left(\mathrm{a}_{\mathrm{w}}: 0.40\right)$ for 366,90 and 43 days at 10,22 , and $38^{\circ} \mathrm{C}$, respectively (Baylis et al., 2004). In wheat flour, while samples were still positive for EHEC after a year of storage at $23^{\circ} \mathrm{C}$, the last positive samples at $35^{\circ} \mathrm{C}$ for EHEC O26 and $\mathrm{O} 157$ upon enrichment were observed at 28 and 49 days, respectively. Interestingly, Salmonella storage at $35^{\circ} \mathrm{C}$ resulted in reductions comparable to the ones from EHEC in our previous study (Forghani et al., 2018), especially in terms of both EHEC and Salmonella reaching unquantifiable range after only a week, post-inoculation. The only difference was that Salmonella was positive upon enrichment up to 98 days which was twice the values observed for EHEC O157 but still much shorter than the $23^{\circ} \mathrm{C}$ storage.

These results are important due to the consistency between Salmonella and EHEC making flour storage at $35^{\circ} \mathrm{C}$ for an appropriate length of time before distribution a possible strategy for the milling industry to reduce the microbial risk for consumers. This can be a helpful strategy since thermal treatment might be harder to perform on industrial scale and it also may not be as effective on Salmonella as it is for EHEC.

The thermal inactivation times were calculated from the time when samples were placed in the heat block due to the minimal ratio of come-up times to our thermal treatment times and for better consistency. The $\delta$-values for Salmonella at 55, 60, 65, and $70^{\circ} \mathrm{C}$ were $152.22,40.78,17.89$, and $17.36 \mathrm{~min}$, respectively. Similar values were reported as 9.97, 5.51, and $2.11 \mathrm{~min}$ at 75, 80, and $85^{\circ} \mathrm{C}$, respectively, for Salmonella enteritidis PT 30 in wheat flour (Smith et al., 2016). The same study also reported $\delta$-values of $8.08,4.97$, and $1.59 \mathrm{~min}$ at 75,80 , and $85^{\circ} \mathrm{C}$, respectively. Interestingly, it was recently reported that in a closed system, the $\mathrm{a}_{\mathrm{w}}$ of flour will significantly increase during the thermal treatment. That study reported that flour with an $\mathrm{a}_{\mathrm{w}}$ of 0.45 at $25^{\circ} \mathrm{C}$ reached an $\mathrm{a}_{\mathrm{w}}$ of approximately 0.71 at $80^{\circ} \mathrm{C}$, in a closed system (Liu et al., 2018).

In another study $\delta$-value of $5.1 \mathrm{~min}$ for pre-fabrication inoculated flour and $4.7 \mathrm{~min}$, for post-fabrication inoculated flour both at $80^{\circ} \mathrm{C}$ were reported, respectively, emphasizing the effect of inoculation protocol on Salmonella thermal death kinetics (Limcharoenchat et al., 2018). However, defining the inoculation protocol that is the closest simulation of real contamination routes based on product type and pathogen of concern remains a challenging subject for further discussion and future research.

The thermal death kinetics of EHEC serogroups obtained in this study (O45, O121, O145) were similar to those obtained in our previous study for EHEC O26, O103, O111, and O157, confirming those observations. The data presented in these two works can be a useful foundation consisting of seven different serogroups information to predict EHEC behavior upon thermal treatment at $55,60,65$, and $70^{\circ} \mathrm{C}$ in wheat flour. Hiramatsu et al. (2005) also reported that E. coli dried on paper disks $\left(\mathrm{a}_{\mathrm{w}}: 0.56\right)$ partially survived after $5 \mathrm{~h}$ exposure to 70 and $80^{\circ} \mathrm{C}$.

As expected, the Weibull model was a good fit overall to describe the thermal death kinetics of EHEC and Salmonella in flour in addition to their long-term survival which has also been previously reported in dry foods (Ma et al., 2009; Santillana Farakos et al., 2014; Forghani et al., 2018). The suitability of Weibull model was further confirmed by solving the Weibull equation, using $\delta$ - and $\beta$-values obtained from the model for each 


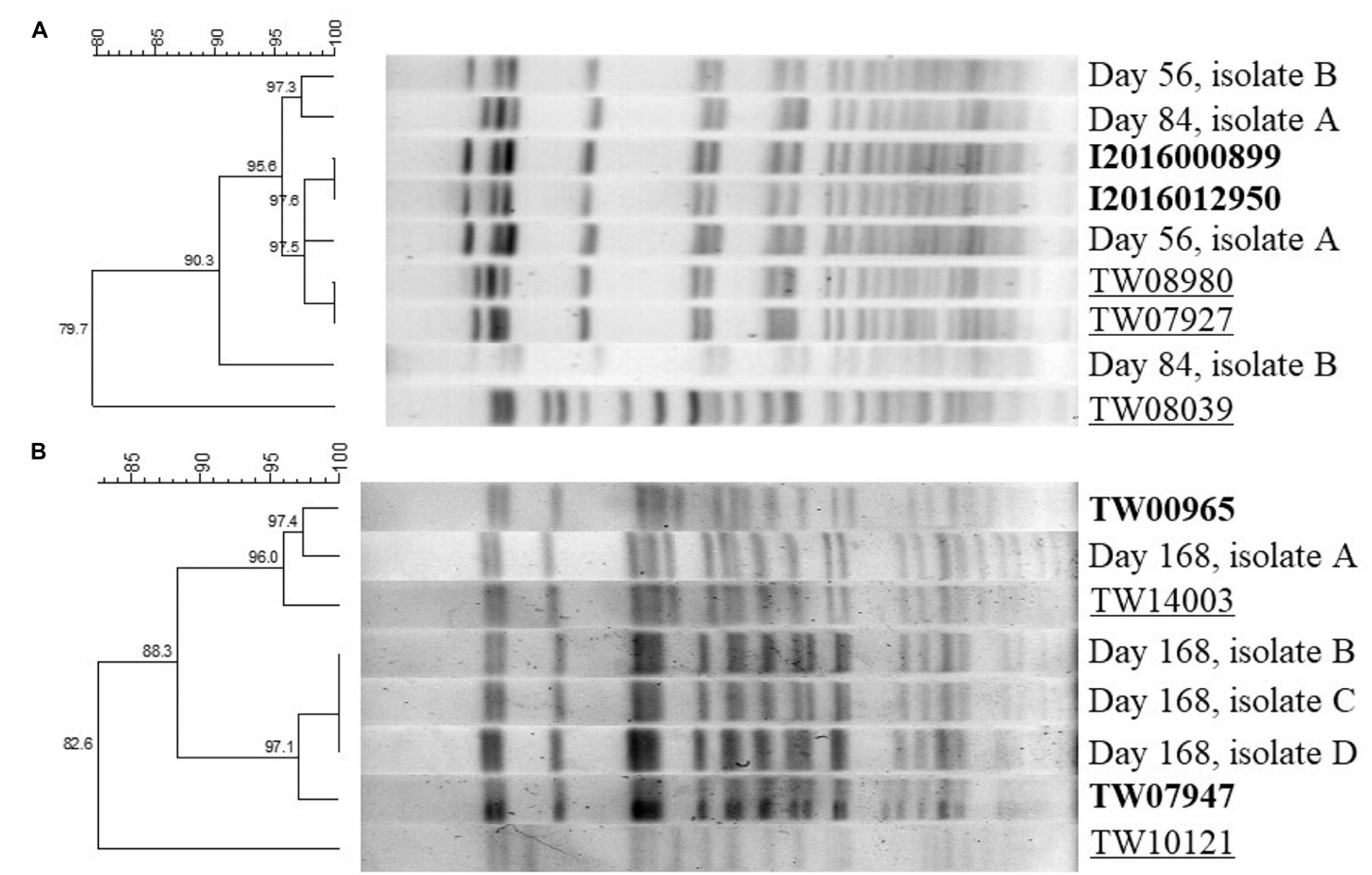

FIGURE 3 | Dendrogram of two EHEC isolates of serogroup 0121 at days 56 and 84 of storage (A) and serogroup 045 at day 168 of storage (B) on pulsed-field gel electrophoresis (PFGE). Bold types represent the previously known patterns of the isolates with maximum similarity to post-storage random isolates. Light types represent the single isolates randomly selected after long-term storage. Underlined types represent the remaining standards that were not recovered at selected random isolates upon storage.

data point and the actual $N_{0}$, resulting in close predictions as shown in Figures 1, 2.

Higher variabilities were observed for Salmonella in comparison to EHEC resulting in lower Adj. $R^{2}$ and greater $\mathrm{SE}$ values in general. Such variations have also previously been reported for Salmonella by Blessington et al. (2013); Beuchat et al. (2017), and Limcharoenchat et al. (2018), who attributed the variations to inoculation method. In an extended study focusing on the effects of inoculation procedures on Salmonella thermal resistance in wheat flour, Hildebrandt et al. (2016) reported that inoculation method impacted repeatability, population stability and inactivation kinetics of Salmonella in wheat flour, regardless of laboratory. It would be a good subject for future studies to assess the possible reasons for such variations.

Another interesting topic for future works would be to identify and study the mechanisms involved in enhanced resistance of Salmonella and EHEC upon dehydration. Although the effect is well known and has been reported in many studies, the information available on the mechanisms involved remains rather scarce. It has been suggested that the complex resistance response during dehydration may involve a coordinated set of mechanisms such as removal of oxygen species, accumulation of amphiphilic solutes and/or proteins, down-regulation of metabolism and accumulation of disaccharides, such as trehalose and sucrose (França et al., 2007). The latter is known as the water replacement hypothesis and has been mentioned as a possible mechanism in Salmonella and Shiga-toxin producing E. coli (Hiramatsu et al., 2005).

Deng et al. (2012) performed a transcriptome sequencing of Salmonella under desiccation and starvation stress concluding that under desiccation Salmonella cells were in dormant state with only $<5 \%$ of the genome being transcribed compared to $78 \%$ in LB broth. In their study, they reported that genes involved in heat and cold shock response, DNA protection and regulatory functions likely play roles in cross protecting Salmonella from desiccation stresses.

Production of osmoprotectants, alternative sigma factors, rRNA degradation, viable but non-culturable state (VBNC) and filamentation are some other strategies that have been suggested to be used by Salmonella to adapt to desiccation (Finn et al., 2013). More recently, Maserati et al. (2018) reported a proteomic analysis of Salmonella in response to desiccation, low $\mathrm{a}_{\mathrm{w}}$ and thermal treatment indicating that ribosomal proteins might be important for additional regulation of the cellular response under these conditions. In another work, they also reported that virulence factors sopD and sseD were critical for Salmonella survival during desiccation (Maserati et al., 2017).

Upon analysis of the PFGE patterns it was observed that during long-term storage the ratio between the five strains used in each inoculum did not remain the same and certain strains were recovered more frequently. Interestingly, in serogroup O121 the two strains that were recovered after PFGE of randomly 
selected colonies at days 56 and 84 of storage (I2016000899, I2016012950) were the two related to a recent flour outbreak (Centers for Disease Control and Prevention, 2016). Same strains were the ones that became dominant through long-term storage. Thus, assessment of the genomic differences between these strains and the other ones in the same serogroup as well as between serogroups would be a good target for future studies, in order to understand the risk factors enabling a strain or serogroup to better survive in flour. In agreement to serogroup O121, the same trend was observed in serogroup O45 resulting in dominance of two strains out of the initial five after 168 days of storage.

\section{CONCLUSION}

In conclusion, findings of the present work further confirmed that EHEC and Salmonella could survive for extended periods in wheat flour stored at typical conditions used at home and commercial settings. Heat treatment is an effective method for mitigating risk of EHEC in flour but is more limited in case of Salmonella. On the other hand, storing produced flour at slightly high temperatures $\left(35^{\circ} \mathrm{C}\right)$ for a minimum period of 2 months before distribution can be an effective substitute

\section{REFERENCES}

Aydin, A., Paulsen, P., and Smulders, F. J. M. (2009). The physico-chemical and microbiological properties of wheat. Turk J. Agric. 33, 445-454. doi: 10.3906/ tar-0901-20

Baylis, C. L., MacPhee, S., Robinson, A. J., Griffiths, R., Lilley, K., and Betts, R. P. (2004). Survival of Escherichia coli O157:H7, O111:H- and O26:H11 in artificially contaminated chocolate and confectionery products. Int. J. Food Microbiol. 96, 35-48. doi: 10.1016/j.ijfoodmicro.2004.03.007

Beier, R. C., Franz, E., Bono, J. L., Mandrell, R. E., Fratamico, P. M., Callaway, T. R., et al. (2016). Disinfectant and antimicrobial susceptibility profiles of the big six non-O157 shiga toxin-producing Escherichia coli strains from food animals and humans. J. Food Prot. 79, 1355-1370. doi: 10.4315/0362-028X.JFP-15-600

Berghofer, L. K., Hocking, A. D., Miskelly, D., and Jansson, E. (2003). Microbiology of wheat and flour milling in Australia. Int. J. Food Microbiol. 85, 137-149. doi: 10.1016/S0168-1605(02)00507-X

Beuchat, L. R., Komitopoulou, E., Beckers, H., Betts, R. P., Bourdichon, F., Fanning, S., et al. (2013). Low-water activity foods: increased concern as vehicles of foodborne pathogens. J. Food Prot. 76, 150-172. doi: 10.4315/0362028X.JFP-12-211

Beuchat, L. R., and Mann, D. A. (2015). Survival of Salmonella in cookie and cracker sandwiches containing inoculated, low-water activity fillings. J. Food Prot. 78, 1828-1834. doi: 10.4315/0362-028X.JFP-15-142

Beuchat, L. R., Mann, D. A., Kelly, C. A., and Ortega, Y. R. (2017). Retention of viability of Salmonella in sucrose as affected by type of inoculum, water activity, and storage temperature. J. Food Prot. 80, 1408-1414. doi: 10.4315/0362-028X. JFP- 16-537

Blessington, T., Mitcham, E. J., and Harris, L. J. (2012). Survival of Salmonella enterica, Escherichia coli O157:H7, and Listeria monocytogenes on inoculated walnut kernels during storage. J. Food Prot. 75, 245-254. doi: 10.4315/0362028X.JFP-11-278

Blessington, T., Theofel, C. G., and Harris, L. J. (2013). A dry-inoculation method for nut kernels. Food Microbiol. 33, 292-297. doi: 10.1016/j.fm.2012.09.009

Brar, P. K., Proano, L. G., Friedrich, L. M., Harris, L. J., and Danyluk, M. D. (2015). Survival of Salmonella, Escherichia coli O157:H7, and Listeria monocytogenes on raw peanut and pecan kernels stored at $-24,4$, and 22 oC. J. Food Prot. 78, 323-332. doi: 10.4315/0362-028X.JFP-14-327 strategy affecting both EHEC and Salmonella. Results from this study further improve our knowledge regarding risk assessment and management, such as predicting thermal process lethality of EHEC and Salmonella in flour.

\section{AUTHOR CONTRIBUTIONS}

FF and FD-G designed the study, conceived the experiment design, analyzed and interpreted the data, and drafted the manuscript. FF, MB, J-YL, AP, and AF performed the experiments. AP also helped with editing the manuscript.

\section{FUNDING}

This study was funded by the Center for Food Safety, University of Georgia.

\section{ACKNOWLEDGMENTS}

The authors would like to thank David A. Mann for his kind technical assistance with PFGE.

Canadian Food Inspection Agency (2017a). Updated Food Recall Warning Various Brands of Flour and Flour Products Recalled due to E. coli O121. Available at: http://www.inspection.gc.ca/about-the-cfia/newsroom/ food-recall-warnings/complete-listing/2017-04-16/eng/1492408217395/ 1492408220892

Canadian Food Inspection Agency (2017b). Updated Food Recall Warning Various Brands of Pie and Tart Shells Recalled due to E. coli O121. Available at: https://www.newswire.ca/news-releases/updated-food-recall-warning--various-brands-of-pie- and-tart-shells-recalled-due-to-e-coli-o121626054513.html

Centers for Disease Control and Prevention (1998). Multistate outbreak of Salmonella serotype agona infections linked to toasted oats cereal - Unites States, April-May, 1998. Morb. Mortal. Wkly. Rep. 47, 462-464.

Centers for Disease Control and Prevention (2009). Multistate outbreak of Salmonella infections associated with peanut butter and peanut buttercontaning products - United States, 2008-2009. Morb. Mortal. Wkly. Rep. 58, 85-90.

Centers for Disease Control and Prevention (2016). Multistate Outbreak of Shiga Toxin-Producing Escherichia coli infections linked to flour (final update). Available at: https://www.cdc.gov/ecoli/2016/o121-06-16/index.html

Crowe, S. J., Bottichio, L., Shade, L. N., Whitney, B. M., Corral, N., Melius, B., et al. (2017). Shiga toxin-producing E. coli infections associated with flour. N. Engl. J. Med. 377, 2036-2043. doi: 10.1056/NEJMoa1615910

Deng, X., Li, Z., and Zhang, W. (2012). Transcriptome sequencing of Salmonella enterica serovar enteritidis under desiccation and starvation stress in peanut oil. Food Microbiol. 30, 311-315. doi: 10.1016/j.fm.2011. 11.001

Eglezos, S. (2010). Microbiological quality of wheat grain and flour from two mills in Queensland, Australia. J. Food Prot. 73, 1533-1536. doi: 10.4315/0362-028X73.8.1533

Esbelin, J., Santos, T., and Michel, H. (2018). Desiccation: an environmental and food industry stress that bacteria commonly face. Food Microbiol. 69, 82-88. doi: 10.1016/j.fm.2017.07.017

Finn, S., Condell, O., McClure, P., Amézquita, A., and Fanning, S. (2013). Mechanisms of survival, responses, and sources of salmonella in lowmoisture environments. Front. Microbiol. 4:331. doi: 10.3389/fmicb.2013. 00331 
Forghani, F., den Bakker, M., Futral, A. N., and Diez-Gonzalez, F. (2018). Longterm survival and thermal death kinetics of enterohemorrhagic Escherichia coli serogroups $\mathrm{O} 26, \mathrm{O} 103, \mathrm{O} 111$, and $\mathrm{O} 157$ in wheat flour. Appl. Environ. Microbiol. 84:e0283-18. doi: 10.1128/AEM.00283-18

França, M., Panek, A., and Eleutherio, E. (2007). Oxidative stress and its effects during dehydration. Comp. Biochem. Physiol. 146, 621-631. doi: 10.1016/j.cbpa. 2006.02.030

Geeraerd, A. H., Valdramidis, V. P., and Van Impe, J. F. (2005). GInaFiT, a freeware tool to assess non-log-linear microbial survivor curves. Int. J. Food Microbiol. 102, 95-105. doi: 10.1016/j.ijfoodmicro.2004.11.038

Hildebrandt, I., Marks, B. P., Ryser, E. T., Villa-Rojas, R., Tang, J., Garces-Vega, F. J., et al. (2016). Effects of inoculation procedures on variability and repeatability of thermal resistance of Salmonella in wheat flour. J. Food Prot. 79, 1833-1839. doi: 10.4315/0362-028X.JFP-16-057

Hiramatsu, R., Matsumoto, M., Sakae, K., and Miyazaki, Y. (2005). Ability of shiga toxin-producing Escherichia coli and Salmonella spp. to survive in a desiccation model system and in dry foods. Appl. Environ. Microbiol. 71, 6657-6663. doi: 10.1128/AEM.71.11.6657

Kataoka, A., Enache, E., Black, D. G., Elliott, P. H., Napier, C. D., Podolak, R., et al. (2014). Survival of Salmonella Tennessee, Salmonella typhimurium DT104, and Enterococcus faecium in peanut paste formulations at two different levels of water activity and fat. J. Food Prot. 77, 1252-1259. doi: 10.4315/0362-028X.JFP13-553

Khamis, M. (2014). Characterization and Evaluation of Heat Treated Wheat Flours. Ph.D. dissertation, Kansas State University, Manhattan, NY.

Lambertini, E., Mishra, A., Guo, M., Cao, H., Buchanan, R. L., and Pradhan, A. K. (2016). Modeling the long-term kinetics of Salmonella survival on dry pet food. Food Microbiol. 58, 1-6. doi: 10.1016/j.fm.2016.02.003

Limcharoenchat, P., Buchholz, S. E., James, M. K., Hall, N. O., Ryser, E., and Marks, B. P. (2018). Inoculation protocols influence the thermal resistance of Salmonella Enteritidis PT 30 in fabricated almond, wheat, and date products. J. Food Prot. 81, 606-613. doi: 10.4315/0362-028X.JFP$17-297$

Liu, S., Rojas, R. V., Gray, P., Zhu, M. J., and Tang, J. (2018). Enterococcus faecium as a Salmonella surrogate in the thermal processing of wheat flour: influence of water activity at high temperatures. Food Microbiol. 74, 92-99. doi: 10.1016/j. fm.2018.03.001

Ludwig, K., Sarkim, V., Bitzan, M., Karmali, M. A., Bobrowski, C., Ruder, H., et al. (2002). Shiga toxin-producing Escherichia coli infection and antibodies against stx2 and stx1 in household contacts of children with enteropathic hemolyticuremic syndrome. J. Clin. Microbiol. 40, 1773-1782. doi: 10.1128/JCM.41.11. 4930

Ma, L., Zhang, G., Gerner-Smidt, P., Mantripragada, V., Ezeoke, I., and Doyle, M. P. (2009). Thermal inactivation of Salmonella in peanut butter. J. Food Prot. 72, 1596-1601. doi: 10.4315/0362-028X-72.8.1596

Mäde, D., Geuthner, A.-C., Imming, R., and Wicke, A. (2017). Detection and isolation of shiga-toxin producing Escherichia coli in flour in Germany. J. Consum. Prot. Food Saf. 12, 245-253. doi: 10.1007/s00003-0171113-1

Mafart, P., Couvert, O., Gaillard, S., and Leguerinel, I. (2002). On calculating sterility in thermal preservation methods: application of the Weibull frequency distribution model. Int. J. Food Microbiol. 72, 107-113. doi: 10.1016/S01681605(01)00624-9

Manthey, F. A., Wolf-Hall, C. E., Yalla, S., Vijayakumar, C., and Carlson, D. (2004). Microbial loads, mycotoxins, and quality of durum wheat from the 2001 harvest of the northern plains region of the United States. J. Food Prot. 67, 772-780. doi: 10.4315/0362-028X-67.4.772

Marler, W. (2006). Cold Stone Creamery - Salmonella. Available at: http://www.marlerblog.com/legal-cases/cold-stone-creamery-salmonella/ \#.WVwB8YjytPZ

Maserati, A., Fink, R. C., Lourenco, A., Julius, M. L., and Diez-Gonzalez, F. (2017). General response of Salmonella enterica serovar typhimurium to desiccation: a new role for the virulence factors sopD and sseD in survival. PLoS One 12:e0187692. doi: 10.1371/journal.pone.0187692

Maserati, A., Lourenco, A., Diez-Gonzalez, F., and Fink, R. C. (2018). crossm iTRAQ-Based global proteomic analysis of Salmonella enterica. Appl. Environ. Microbiol. 84, 1-17. doi: 10.1128/AEM. 00393-18
Maturin, L., and Peeler, J. (1998). "Aerobic plate count. Ch. 3," in Food and Drug Administration Bacteriological Analytical Manual, 8th ed. (revision A), (CD-ROM version), ed. R. L. Merker (Gaithersburg, MD: AOAC International).

McCallum, L., Paine, S., Sexton, K., Dufour, M., Dyet, K., Wilson, M., et al. (2013). An outbreak of Salmonella Typhimurium phage type 42 associated with the consumption of raw flour. Foodborne Pathog. Dis. 10, 159-164. doi: 10.1089/ fpd.2012.1282

Mondani, L., Roupioz, Y., Delannoy, S., Fach, P., and Livache, T. (2014). Simultaneous enrichment and optical detection of low levels of stressed Escherichia coli O157:H7 in food matrices. J. Appl. Microbiol. 117, 537-546. doi: $10.1111 /$ jam. 12522

Neil, K. P., Biggerstaff, G., MacDonald, J. K., Trees, E., Medus, C., Musser, K. A., et al. (2012). A novel vehicle for transmission of Escherichia coli O157:H7 to humans: multistate outbreak of E. coli O157:H7 infections associated with consumption of ready-to-bake commercial prepackaged cookie dough-United States, 2009. Clin. Infect. Dis. 54, 511-518. doi: 10.1093/cid/ cir831

Ozawa, M., Kato, Y., and Seguchi, M. (2009). Investigation of dry-heated hard and soft wheat flour. Starch Staerke 61, 398-406. doi: 10.1002/star.2008 00142

Podolak, R., Enache, E., Stone, W., Black, D. G., and Elliott, P. H. (2012). Sources and risk factors for contamination, survival, persistence, and heat resistance of Salmonella in low-moisture foods. J. Food Prot. 72, 1919-1936. doi: 10.4315/ 0362-028X-61.8.969

Rachon, G., Peñaloza, W., and Gibbs, P. A. (2016). Inactivation of Salmonella, Listeria monocytogenes and Enterococcus faecium NRRL B-2354 in a selection of low moisture foods. Int. J. Food Microbiol. 231, 16-25. doi: 10.1016/j. ijfoodmicro.2016.04.022

Rayman, M. K., D’aoust, J.-Y., Aris, B., Maishment, C., and Wasik, R. (1979). Survival of microorganisms in stored pasta. J. Food Prot. 42, 330-334. doi: 10.4315/0362-028X-42.4.330

Richter, K. S., Dorneanu, E., Eskridge, K. M., and Rao, C. S. (1993). Microbiological quality of flours. Cereal Foods World 38, 367-369.

Riley, L. W., Remis, R. S., Helgerson, S. D., McGee, H. B., Wells, J. G., Davis, B. R., et al. (1983). Hemorrhagic colitis associated with a rare Escherichia coli serotype. N. Engl. J. Med. 308, 681-685. doi: 10.1056/NEJM198303243 081203

Rose, D. J., Bianchini, A., Martinez, B., and Flores, R. A. (2012). Methods for reducing microbial contamination of wheat flour and effects on functionality. Cereal Foods World 57, 104-109. doi: 10.1094/CFW-57-3-0104

Sabillón Galeas, L. E. (2014). Understanding the Factors Affecting Microbiological Quality of Wheat Milled Products: From Wheat Fields to Milling Operations. Available at: http://digitalcommons.unl.edu/foodscidiss/49

Santillana Farakos, S. M., Frank, J. F., and Schaffner, D. W. (2013). Modeling the influence of temperature, water activity and water mobility on the persistence of Salmonella in low-moisture foods. Int. J. Food Microbiol. 166, 280-293. doi: 10.1016/j.ijfoodmicro.2013.07.007

Santillana Farakos, S. M., Schaffner, D. W., and Frank, J. F. (2014). Predicting survival of Salmonella in low-water activity foods: an analysis of literature data. J. Food Prot. 77, 1448-1461. doi: 10.4315/0362-028X.JFP-14-013

Smith, D. F., Hildebrandt, I. M., Casulli, K. E., Dolan, K. D., and Marks, B. P. (2016). Modeling the effect of temperature and water activity on the thermal resistance of Salmonella enteritidis PT 30 in wheat flour. J. Food Prot. 79, 2058-2065. doi: 10.4315/0362-028X.JFP-16-155

Sperber, W. H. (2007). Role of microbiological guidelines in the production and commercial use of milled cereal grains: a practical approach for the 21st century. J. Food Prot. 70, 1041-1053. doi: 10.4315/0362-028X-70. 4.1041

Sudha, M. L., Soumya, C., and Prabhasankar, P. (2016). Use of dry-moist heat effects to improve the functionality, immunogenicity of whole wheat flour and its application in bread making. J. Cereal Sci. 69, 313-320. doi: 10.1016/j.jcs. 2016.04.010

Taylor, M. H., Tsai, H. C., Rasco, B., Tang, J., and Zhu, M. J. (2018). Stability of Listeria monocytogenes in wheat flour during extended storage and isothermal treatment. Food Control 91, 434-439. doi: 10.1016/j.foodcont.2018. 04.008

U.S. Food \& Drug Administration (2005). Bulletin to the Food Service and Retail Food Store Industry Regarding Cake Batter ice ice Cream and Similar Products. 
Available at: http://www.salmonellablog.com/salmonella-watch/bulletin-tothe-food-service- and-retail-food-store-industry-regarding-cake-batter-icecrea

Wang, H., Cehn, Z., and Jiang, G. X. (2016). Improving the enrichment and plating methods for rapid detection of non-O157 shiga toxin-producing Escherichia coli in dairy compost. J. Food Prot. 79, 413-420. doi: 10.4315/0362-028X.JFP$15-249$

Xu, J., Tang, J., Jin, Y., Song, J., Yang, R., Sablani, S. S., et al. (2018). High temperature water activity as a key factor influencing survival of Salmonella Enteritidis PT30 in thermal processing. Food Control 98, 520-528. doi: 10.1016/ j.foodcont.2018.11.054
Conflict of Interest Statement: The authors declare that the research was conducted in the absence of any commercial or financial relationships that could be construed as a potential conflict of interest.

Copyright (๑) 2019 Forghani, den Bakker, Liao, Payton, Futral and Diez-Gonzalez. This is an open-access article distributed under the terms of the Creative Commons Attribution License (CC BY). The use, distribution or reproduction in other forums is permitted, provided the original author(s) and the copyright owner(s) are credited and that the original publication in this journal is cited, in accordance with accepted academic practice. No use, distribution or reproduction is permitted which does not comply with these terms. 